\title{
A second backbone: the contribution of a buried asparagine ladder to the global and local stability of a leucine-rich repeat protein
}

Sean A. Klein ${ }^{1}$, Ananya Majumdar ${ }^{2}$, Doug Barrick ${ }^{1 *}$

${ }^{1}$ T.C. Jenkins Department of Biophysics, Johns Hopkins University, Baltimore, MD 21218 USA;

${ }^{2}$ The Johns Hopkins University Biomolecular NMR Center, Johns Hopkins University,

Baltimore, Maryland, 21218; *Correspondence to: Prof. Doug Barrick, T.C. Jenkins Department of Biophysics, Johns Hopkins University, 3400 N. Charles St, Baltimore, MD 21218. E-mail:

barrick@jhu.edu 


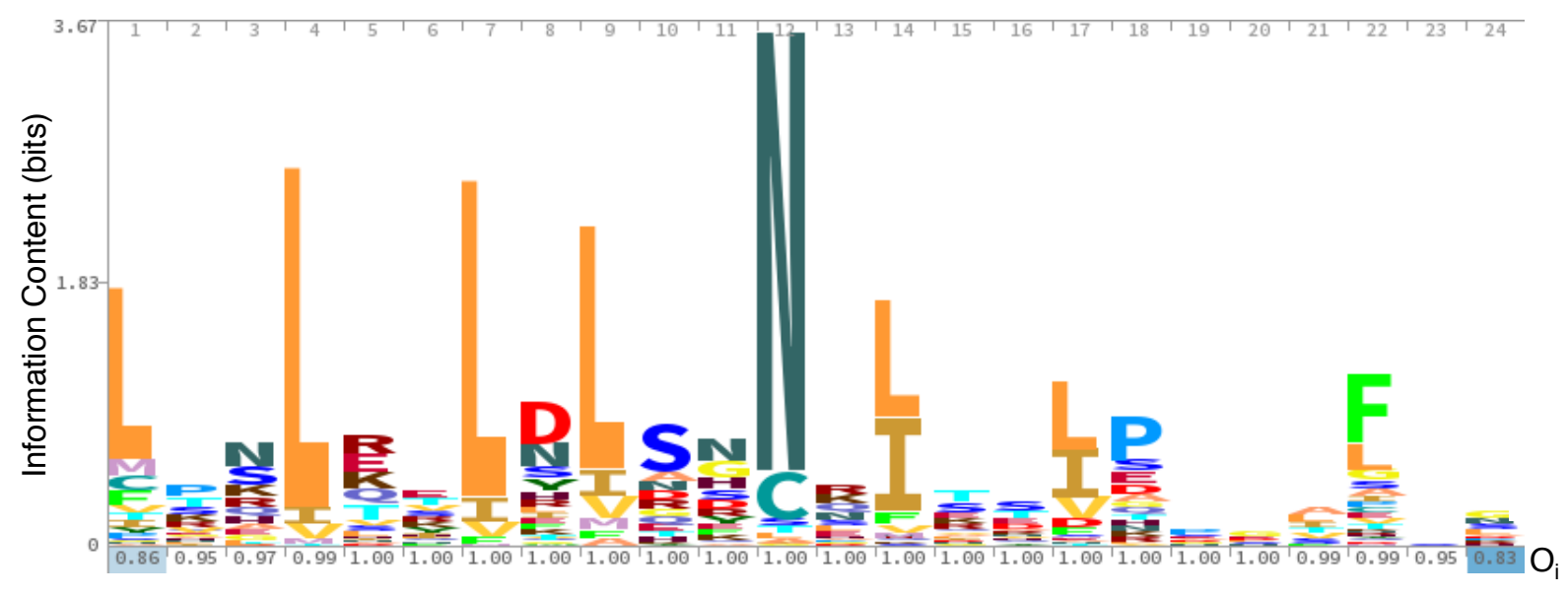

Figure S1. Sequence conservation in the LRR protein family. (A) HMM $\log 0{ }^{1}$ for LRR_TYP and LRR families from the SMART database ${ }^{2}$. A starting set of 428,451 LRR sequences from the UniProt, Ensembl, or STRING databases was culled to retain sequences from the typical LRR subfamily (to which pp32 LRRs best align) by selecting for repeats from animals or fungi that were between 20 and 27 residues in length ${ }^{3}$. Using CD-Hit ${ }^{4}$, sequences with greater than $80 \%$ identity were removed and the remaining sequences were aligned using MAFFT ${ }^{5}$ with the gap opening and elongation penalties maximized. Occupancies (the fraction of sequences with gaps at position $i ; \mathrm{O}_{\mathrm{i}}$ ) are tabulated beneath each letter stack. Positions with occupancies less than $50 \%$ are not shown. The decrease in occupancy for $\mathrm{N}$ - and C-terminal positions likely arises from variation in LRR length within the final data set. 


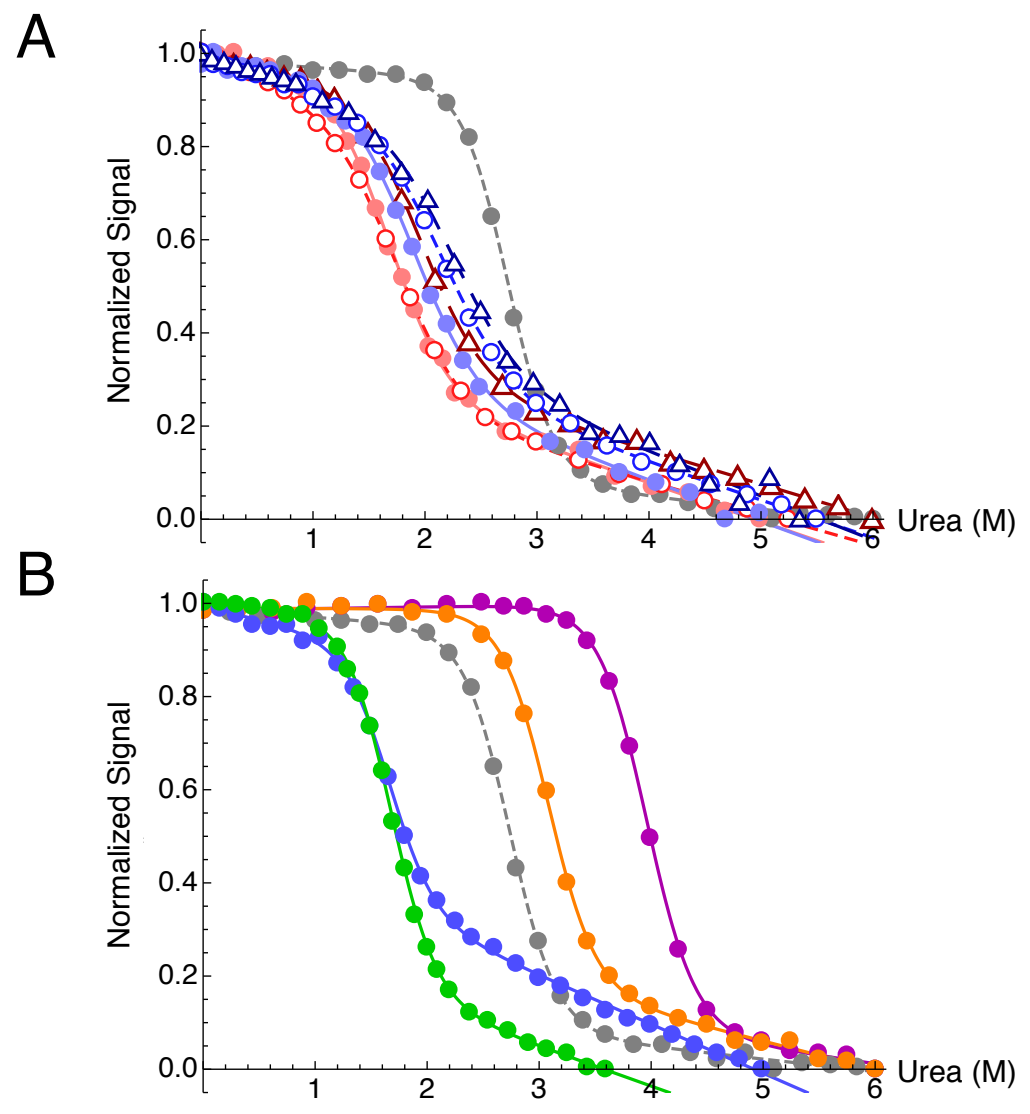

Figure S2. Urea-induced unfolding of asparagine ladder and peripheral variants of pp32. Urea melts of asparagine ladder variants depicted as in Figure 1B, D. Transitions were monitored by $\mathrm{CD}$ at $220 \mathrm{~nm}$ and were fitted using a two-state model (curves). Data are reported in units of normalized ellipticity for asparagine ladder substitutions (A) and peripheral variants (B) by setting the highest and lowest $\mathrm{CD}$ values to one and zero respectively, and scaling all other points to these two limits. Conditions: $\sim 3-5 \mu \mathrm{M}$ protein, $20 \mathrm{mM} \mathrm{NaPO}_{4}, 150 \mathrm{mM} \mathrm{NaCl}, 0.1 \mathrm{mM}$ TCEP, pH 7.8, $20{ }^{\circ} \mathrm{C}$. 


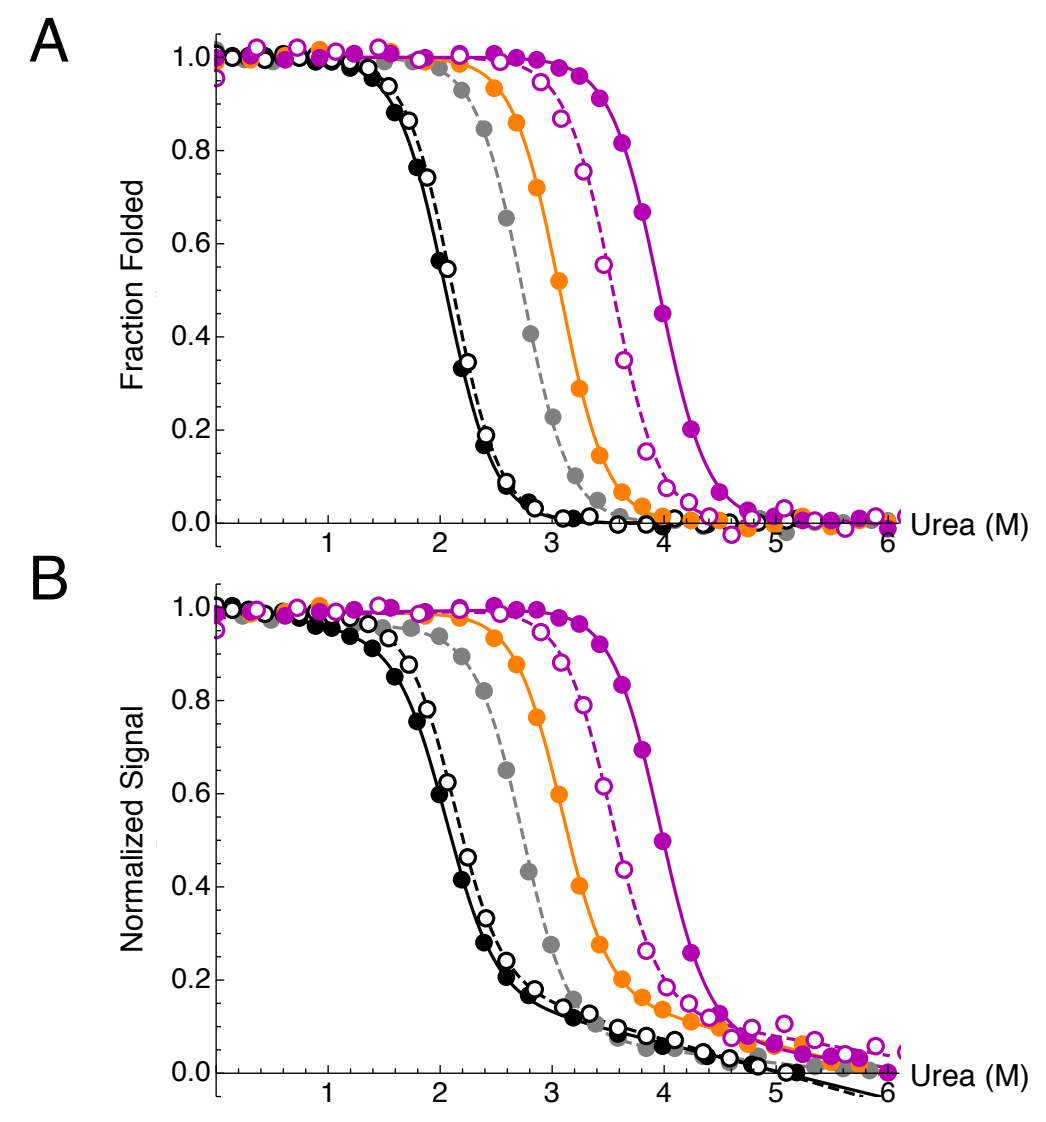

Figure S3. Urea-induced unfolding of asparagine ladder extending and T49 substitutions in pp32. Urea denaturation of wild-type (dashed gray), N-terminal asparagine ladder extending substitutions (S27N, solid black; V52N, dashed black), C-terminal asparagine ladder extending substitutions (C123N, orange), and T49 substitutions (T49L, purple; T49V, dashed purple). Transitions were monitored by CD at $220 \mathrm{~nm}$ and were fitted using a two-state model (curves). Data and curves are transformed to (A) fraction folded using fitted baseline parameters or (B) normalized ellipticity by setting the highest and lowest $\mathrm{CD}$ values to one and zero respectively, and scaling all other points to these two limits (B). Conditions: $\sim 3-5 \mu \mathrm{M}$ protein, $20 \mathrm{mM} \mathrm{NaPO}_{4}$, $150 \mathrm{mM} \mathrm{NaCl}, 0.1 \mathrm{mM}$ TCEP, $\mathrm{pH} 7.8,20{ }^{\circ} \mathrm{C}$. 


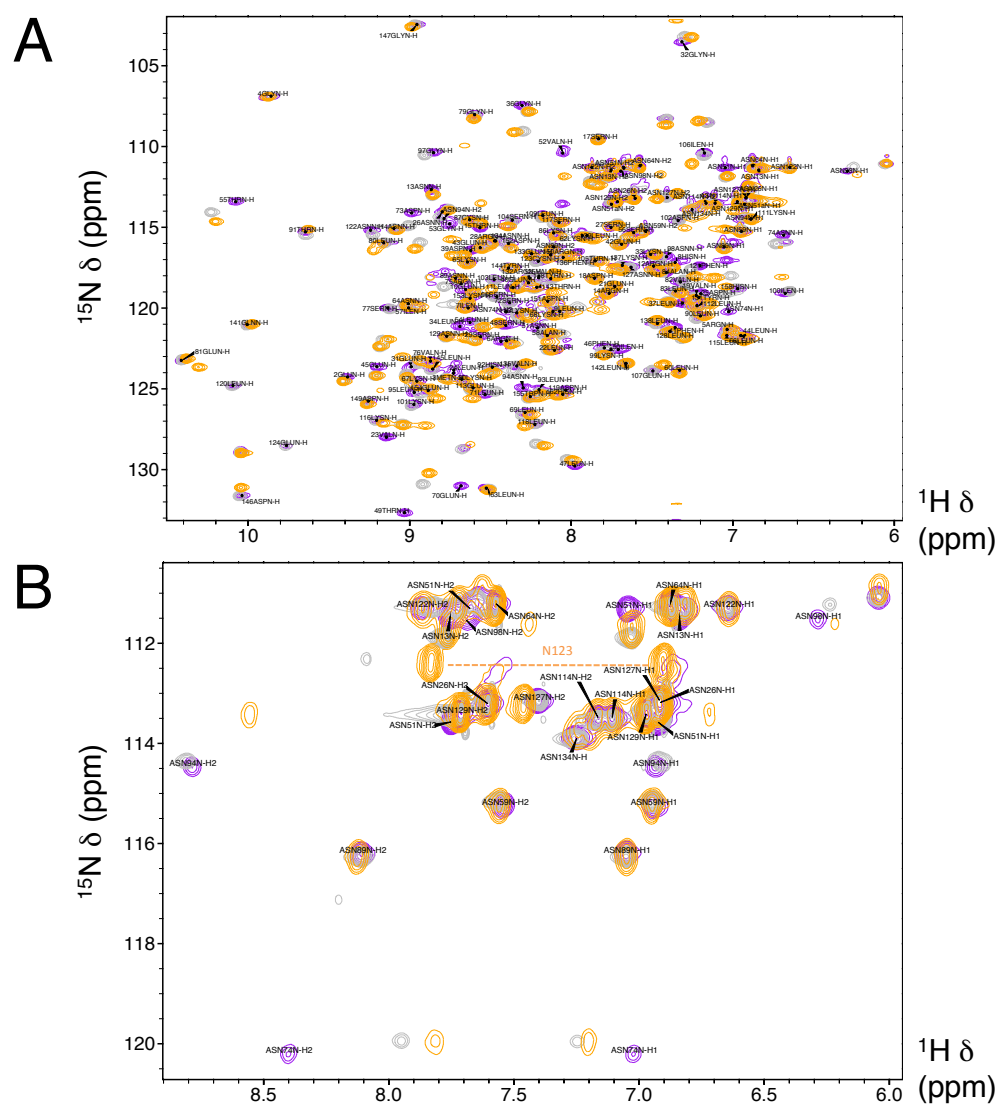

Figure S4. Backbone NH and $\mathrm{NH}_{2}$-filtered HSQC spectra of pp32 variants. (A) Overlay of ${ }^{1} \mathrm{H}-{ }^{15} \mathrm{~N}$ HSQC spectra for select pp32 variants (wild-type, gray; C123N, orange; T49L, purple). Assignments are shown for the T49L variant, as this protein had the largest number of assignable resonances. (B) Overlay of $\mathrm{NH}_{2}$-filtered HSQC spectra colored and labeled as in (A). The new N123 peak in the $\mathrm{C} 123 \mathrm{~N}$ variant is indicated with an orange dashed line and label. Conditions: $\sim 600-800 \mu \mathrm{M}$ protein, $10 \% \mathrm{D}_{2} \mathrm{O}, 20 \mathrm{mM} \mathrm{NaPO}_{4}, 50 \mathrm{mM} \mathrm{NaCl}, 0.1 \mathrm{mM}$ TCEP, pH 6.8, $20{ }^{\circ} \mathrm{C}$. 

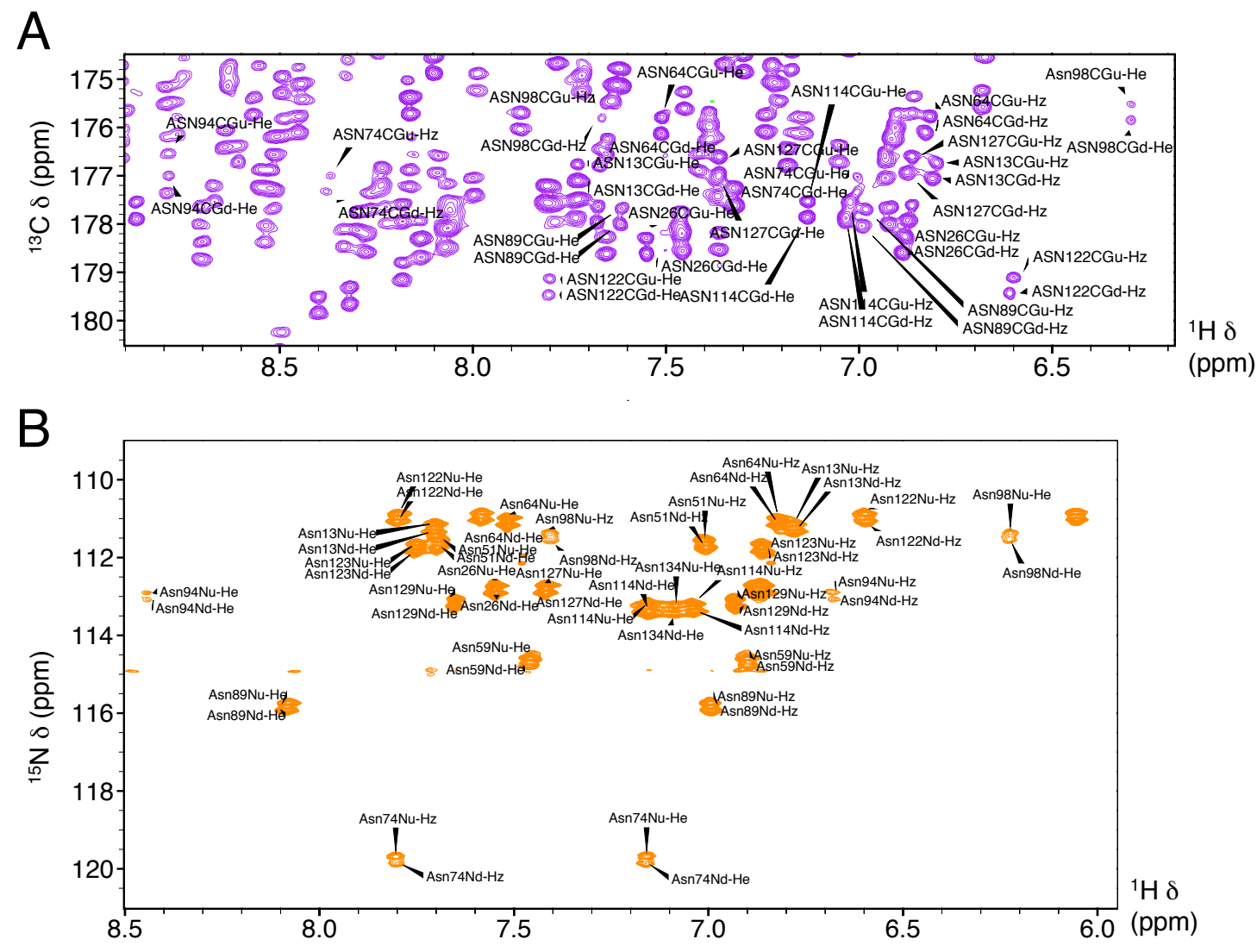

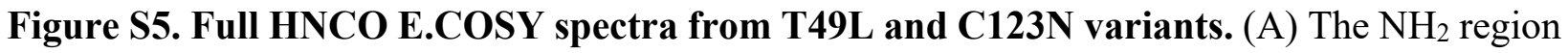
of the HNCO E.COSY spectrum of the T49L variant of pp32. In this experiment, $\mathrm{C}_{\beta}$ spin states are not perturbed; therefore, cross peaks in $\omega_{1}$ and $\omega_{2}$ couple to the same $C_{\beta}$ spin state (i.e., $C_{\gamma} C_{\beta}{ }^{\alpha}$ and $\left.\mathrm{H}_{\mathrm{E} / \mathrm{Z}} \mathrm{C}_{\beta}{ }^{\alpha}\right)$. The large positive ${ }^{1} \mathrm{~J}\left(\mathrm{C}_{\beta}-\mathrm{C}_{\gamma}\right)$ coupling allows the small ${ }^{3} \mathrm{~J}\left(\mathrm{H}_{\mathrm{Z}}-\mathrm{C}_{\beta}\right)(5-10 \mathrm{~Hz})$ and ${ }^{3} \mathrm{~J}\left(\mathrm{H}_{\mathrm{E}}-\mathrm{C}_{\beta}\right)$ (effectively $0 \mathrm{~Hz}$ ) to be determined, thereby assigning the asparagine $\mathrm{H}_{\mathrm{Z}}$ and $\mathrm{H}_{\mathrm{E}}$ protons. Resolved asparagine side chain peaks are labeled; unlabeled peaks are residual signals from backbone amides. (B) Full $\mathrm{C}_{\gamma} \mathrm{O}$-coupled $\mathrm{NH}_{2}$-HSQC E.COSY for the $\mathrm{C} 123 \mathrm{~N}$ variant of pp32. As in (A), the $\mathrm{C}_{\gamma}$ spin states are unperturbed. The large ${ }^{1} \mathrm{~J}\left(\mathrm{~N}_{\delta 2}-\mathrm{C}_{\gamma}\right)$ allows the small positive ${ }^{2} \mathrm{~J}\left(\mathrm{H}_{\mathrm{E}}-\mathrm{C}_{\gamma}\right)$ $(\sim 1-5 \mathrm{~Hz})$ and negative ${ }^{2} \mathrm{~J}\left(\mathrm{H}_{\mathrm{Z}}-\mathrm{C}_{\gamma}\right)(\sim-1$ to $-5 \mathrm{~Hz})$ to be determined, thereby assigning the asparagine $\mathrm{H}_{\mathrm{Z}}$ and $\mathrm{H}_{\mathrm{E}}$ protons. $\mathrm{Nu}=$ upfield ${ }^{15} \mathrm{~N}$ doublet peak, $\mathrm{Nd}=$ downfield ${ }^{15} \mathrm{~N}$ doublet peak. Conditions: $\sim 600 \mu \mathrm{M}$ protein, $50 \% \mathrm{D}_{2} \mathrm{O}, 20 \mathrm{mM} \mathrm{NaPO}_{4}, 50 \mathrm{mM} \mathrm{NaCl}, 0.1 \mathrm{mM}$ TCEP, $\mathrm{pH} 6.8$ (after adjustment for $\left.\mathrm{D}_{2} \mathrm{O}\right), 35^{\circ} \mathrm{C}$. 

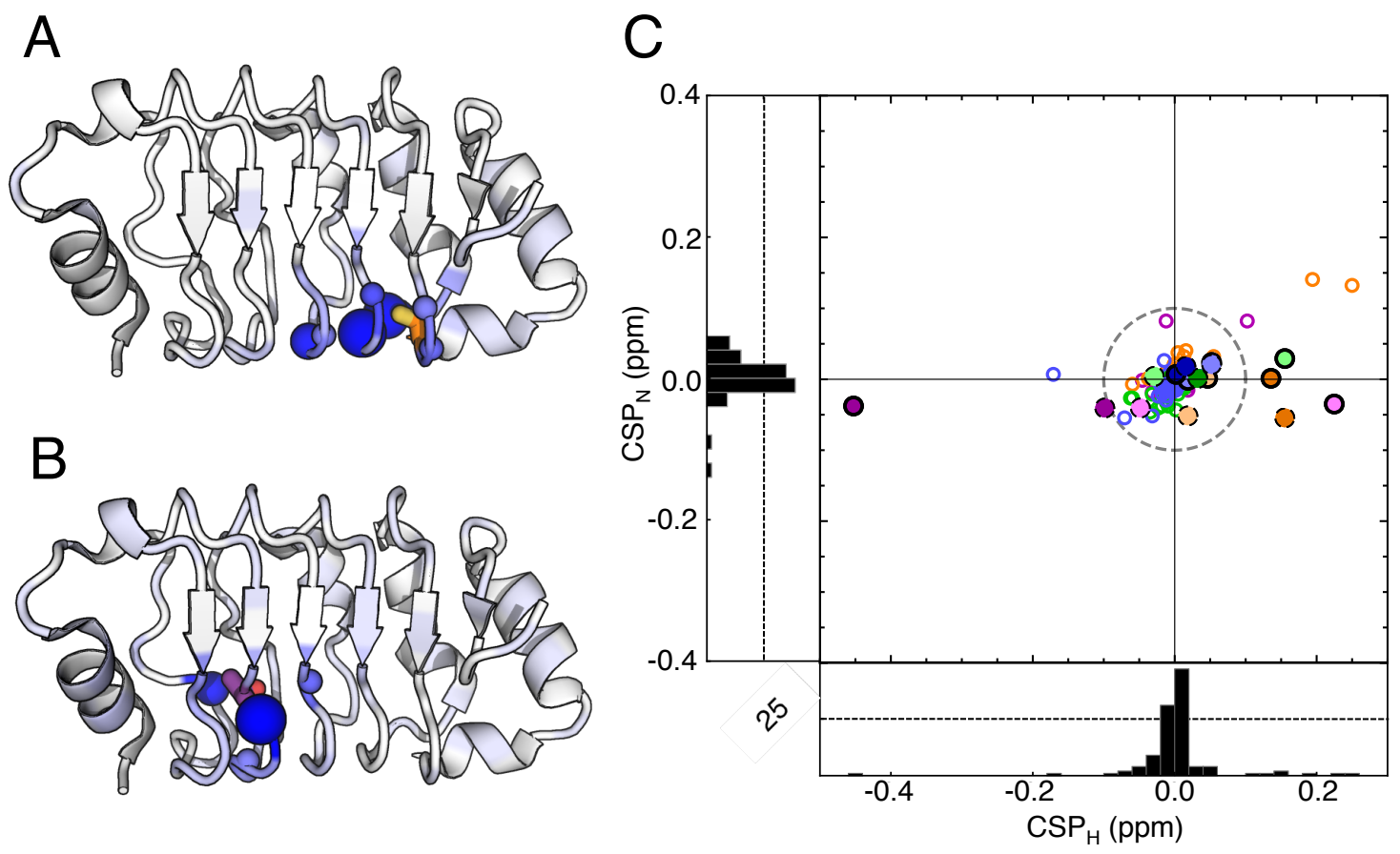

Figure S6. Backbone amide and asparagine side chain chemical shift perturbations in pp32 variants. (A) C123N CSPs mapped to the pp32 structure (PDB ID: 4XOS). The magnitude of the $\mathrm{CSP}$ at each residue is indicated by the blue shading intensity. Large spheres show residues where CSPs exceed $3 \sigma_{\text {CSP }}$ (where $\sigma_{\text {CSP }}$ is the standard deviation in chemical shift perturbation values), medium spheres show residues where $2 \sigma_{\mathrm{CSP}}<\mathrm{CSP}<3 \sigma_{\mathrm{CSP}}$, and small spheres show residues where $1 \sigma_{\text {CSP }}<$ CSP $<2 \sigma_{\text {CSP. }}$ (B) T49L CSPs mapped to the pp32 structure. Color mapping and sphere size cutoffs are as in (A). (C) ${ }^{1} \mathrm{H}-{ }^{15} \mathrm{~N}$ CSPs for all resolvable side chain protons. Non-ladder asparagines are shown as empty circles. Ladder asparagines 74 and 98 are shown as filled circles with solid and dashed outlines, respectively; $\mathrm{Hz}_{\mathrm{Z}}$ and $\mathrm{H}_{\mathrm{E}}$ have dark and light shading, respectively. T49L, purple; L69A, green; C123N, orange; YD, blue. As in an HSQC spectrum, quadrants to the left indicate increased ${ }^{1} \mathrm{H}$ deshielding in the variants compared to wild-type pp32, and lower quadrants indicate increased ${ }^{15} \mathrm{~N}$ deshielding. The dashed gray circle is one $\sigma$ from the median. All distances are measured in ${ }^{1} \mathrm{H}$ units of ppm with a scaling factor of 0.14 in the ${ }^{15} \mathrm{~N}$-dimension. Histograms represent the number of side chain protons with a particular $\operatorname{CSP}_{\mathrm{N}}$ or $\mathrm{CSP}_{\mathrm{H}}$ value; the dashed line across each histogram shows a count of 25 CSPs. Conditions: $\sim 600 \mu \mathrm{M}$ protein, 20 $\mathrm{mM} \mathrm{NaPO}_{4}, 50 \mathrm{mM} \mathrm{NaCl}, 0.1 \mathrm{mM}$ TCEP, $\mathrm{pH} 6.8,20^{\circ} \mathrm{C}$. 


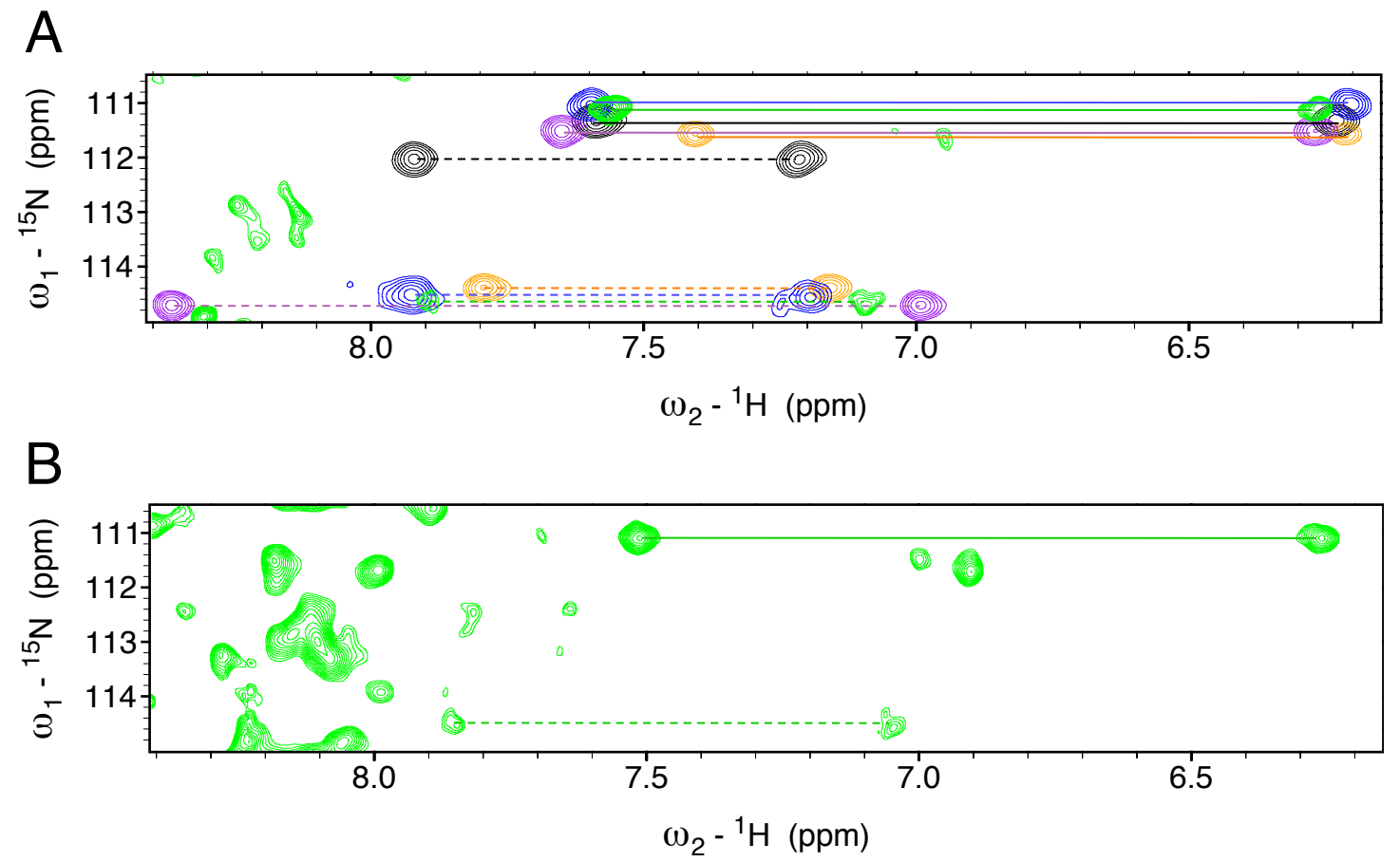

Figure S7. $\mathrm{NH}_{2}$-filtered HSQC spectra for partly exchanged samples of wild-type pp32 and variants. (A) $\mathrm{NH}_{2}$-filtered $\mathrm{HSQC}$ spectra from the first hydrogen exchange time point for wildtype pp32 and variants. Peaks are folded in the ${ }^{15} \mathrm{~N}$ dimension as a result of a decreased spectral width to shorten data acquisition time. Colors are as in Figure 2; dashed lines connect N74 resonances, solid lines connect N98 resonances. L69A peaks are from a hydrogen exchange experiment at $20^{\circ} \mathrm{C}$ with reduced background noise (see B below for $30^{\circ} \mathrm{C}$ experiment). (B) $\mathrm{NH}_{2}$ filtered HSQC spectra from hydrogen exchange first time point for L69A at $30^{\circ} \mathrm{C}$. Assignments of the N74 resonances of L69A were corroborated by comparison to an $\mathrm{NH}_{2}$-filtered ${ }^{1} \mathrm{H}-{ }^{15} \mathrm{~N}$ HSQC spectrum with a higher signal-to-noise ratio. Conditions: $\sim 800 \mu \mathrm{M}$ protein, $100 \% \mathrm{D}_{2} \mathrm{O}, 150 \mathrm{mM}$ $\mathrm{NaPO}_{4}, 50 \mathrm{mM} \mathrm{NaCl}, 0.1 \mathrm{mM}$ TCEP, $30{ }^{\circ} \mathrm{C}\left(20{ }^{\circ} \mathrm{C}\right.$ for L69A in (A)) $\mathrm{pH} 6.8$ (after accounting for $\left.\mathrm{D}_{2} \mathrm{O}\right)$. 

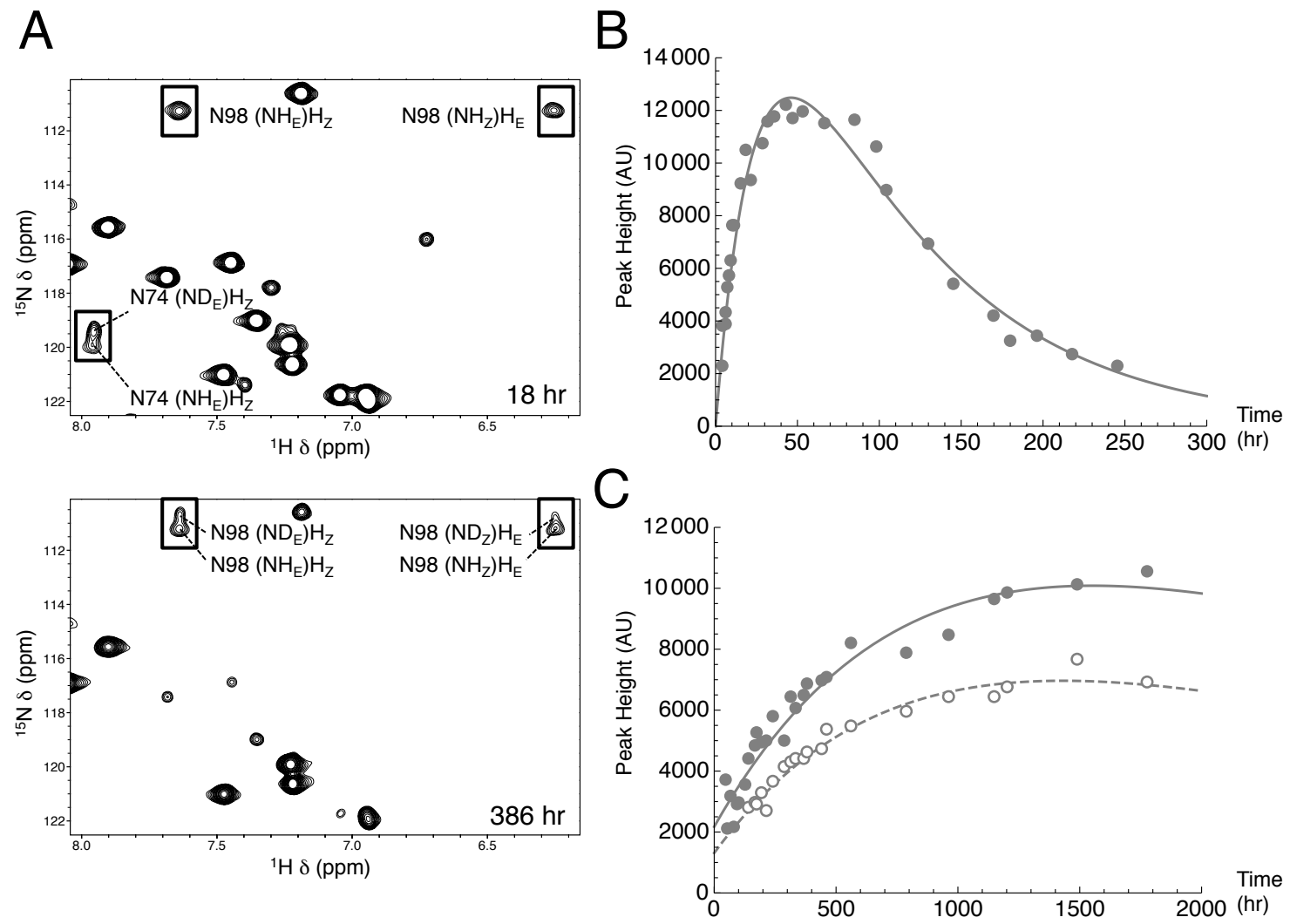

Figure S8. Hydrogen exchange of ladder asparagine side chains from unfiltered ${ }^{1} \mathbf{H}-{ }^{15} \mathbf{N}$ HSQC spectra. (A) Unfiltered ${ }^{1} \mathrm{H}_{-}{ }^{15} \mathrm{~N}$ HSQC spectra of wild-type pp32 after 18 (top) and 386 hours (bottom). $\mathrm{NH}_{2}$ and NHD peaks are resolved by a slight shift of the NHD species to lower frequency in the ${ }^{15} \mathrm{~N}$ dimension. (B) $\mathrm{N} 74\left(\mathrm{ND}_{\mathrm{E}}\right) \mathrm{H}_{\mathrm{Z}}$ peak intensity as a function of exchange time for wild-type pp32, fitted with eq 3 (solid curve). (C) $\mathrm{N} 98\left(\mathrm{ND}_{\mathrm{E}}\right) \mathrm{H}_{Z}$ (filled circles) and $\left(\mathrm{ND}_{\mathrm{Z}}\right) \mathrm{H}_{\mathrm{E}}$ (empty circles) peak height as a function of exchange time for wild-type pp32globally fitted with eqs 3 and 4 (solid and dashed curves). Unlike N74 (B), the individual exchange profiles for the N98 NHD species only show the build-up phase due to the slow exchange at N98. However, the $\left(\mathrm{N}_{\mathrm{D}} \mathrm{Z}\right) \mathrm{H}_{\mathrm{E}}$ and $\left(\mathrm{ND}_{\mathrm{E}}\right) \mathrm{H}_{\mathrm{Z}}$ build-ups report on different rate constants ( $\mathrm{k}_{\mathrm{ex}, \mathrm{HE}}$ and $\mathrm{k}_{\mathrm{ex}, \mathrm{HZ}}$, respectively), allowing both constants to be determined accurately from the 2000 hour exchange profile. Conditions: $800 \mu \mathrm{M}$ protein, $100 \% \mathrm{D}_{2} \mathrm{O}, 20 \mathrm{mM} \mathrm{NaPO}_{4}, 50 \mathrm{mM} \mathrm{NaCl}, 0.2 \mathrm{mM} \mathrm{TCEP}, 20^{\circ} \mathrm{C}, \mathrm{pH}$ 6.7 (after accounting for $\mathrm{D}_{2} \mathrm{O}$ ). 


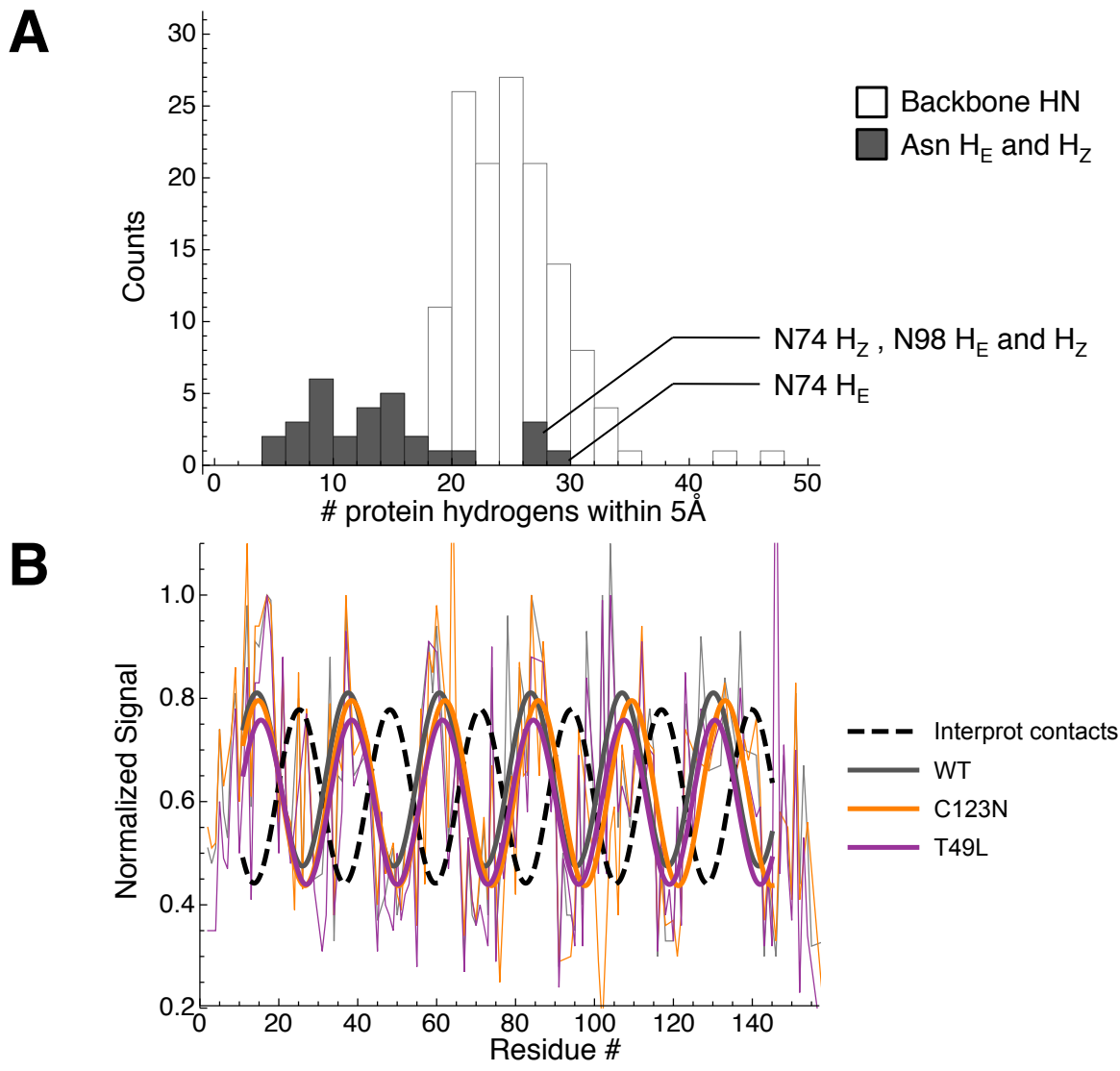

Figure S9. Correlation between interproton contacts and ${ }^{1} \mathrm{H}-{ }^{15} \mathrm{~N}$ HSQC peak heights. (A) Histogram of the number of protein hydrogens (excluding waters) within $5 \AA$ of backbone amide hydrogens (white bars) and asparagine side chain $\mathrm{H}_{\mathrm{E}}$ and $\mathrm{H}_{\mathrm{Z}}$ (gray bars) in the high-resolution crystal structure of pp32 (PDB ID: 4XOS). (B) Comparison of cosine function fits to HSQC peak heights (solid curves) and the number of protein hydrogens within $5 \AA$ (dashed curve) in pp32. Peak heights (thin lines) are normalized to the height of the NH peak of residue 17 (one of the five most intense peaks in all variants). The dashed cosine function is fit to the normalized number of interproton contacts to backbone amide hydrogens from (A) as a function of position and is scaled and shifted along the $y$-axis to match the mean and amplitude of the pp32 variants. All fits were limited to residues within the five leucine-rich repeats (residues 11-145) using the function $I(x)=$ $a^{*} \cos \left(2 \pi^{*}(x-c / n)\right)+d$, where $I$ is the intensity, $a$ is the amplitude, $x$ is the residue number, $c$ is a phase term, $n$ is the number of residues per repeating unit, and $d$ is a vertical offset. 


\section{References}

(1) Wheeler, T. J., Clements, J., and Finn, R. D. (2014) Skylign: A tool for creating informative, interactive logos representing sequence alignments and profile hidden Markov models. BMC Bioinformatics 15, 1-9. doi: 10.1186/1471-2105-15-7.

(2) Letunic, I., and Bork, P. (2018) 20 years of the SMART protein domain annotation resource. Nucleic Acids Res. 46, D493-D496.

(3) Kajava, A. V. (1998) Structural diversity of leucine-rich repeat proteins. J. Mol. Biol. 277, 519-527.

(4) Li, W., and Godzik, A. (2006) Cd-hit: A fast program for clustering and comparing large sets of protein or nucleotide sequences. Bioinformatics 22, 1658-1659.

(5) Katoh, K., Rozewicki, J., and Yamada, K. D. (2017) MAFFT online service: multiple sequence alignment, interactive sequence choice and visualization. Brief. Bioinform. 1-7. doi: $10.1093 / \mathrm{bib} / \mathrm{bbx} 108$. 